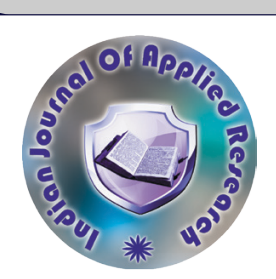

\title{
Oncology
}

\section{HALF LIFE OF CA 125 AS A MARKER OF RESPONSE TO NEO ADJUVANT CHEMOTHERAPY AND PREDICTIVE MODEL OF SURGICAL OUTCOME IN ADVANCED EPITHELIAL OVARIAN CANCER-A SINGLE INSTITUITIONAL STUDY.}

\section{Dr Prem Kumar Devdoss \\ Dr Prasanna Srinivasa Rao H*}

MD, DM, Associate Professor of Medical Oncology Govt. Arignar Anna Memorial Cancer Hospital \& Research Institute, Kanchipuram.

MS, Mch, Assistant Professor of Surgical Oncology Govt. Arignar Anna Memorial Cancer Hospital \& Research Institute, Kanchipuram. *Corresponding Author

ABSTRACT Objective: The objective of this retrospective study is to identify the elimination half life of CA 125 biomarker in women receiving neoadjuvant chemotherapy for newly diagnosed advanced epithelial ovarian cancer at our centre and develop it as a surrogate marker of response to chemotherapy.

Methods: Medical records of women who were newly diagnosed with inoperable advanced ovarian cancer stages III and IV at our centre were selected. Only people with completely documented records in the years 2017 \& 2018 were selected. Clinical information on age, menopausal status, BMI, radiological PCI, stage, histology, chemotherapy drugs used, CA 125 levels before and after neoadjuvant chemotherapy were noted and information analysed.

Only 40 patients were identified meeting all required criteria.

The patients were divided into 3 sets based on CA 125 elimination half life group $1(\mathrm{t} 1 / 2<10$ days), group 2 ( $\mathrm{t} 1 / 2$ 10-20 days) and group 3 ( $\mathrm{t} 1 / 2>20$ days). The base line characters and outcomes of surgery and pathological responses were compared between these groups.

Results: Optimal cytoredcution was possible in 19/21(90.4\%) patients in group 1,6/10(60\%) in group 2 \& $2 / 9(22.2 \%)$ in group 3 . Clinical complete response was found in $12 / 21(57.1 \%), 2 / 10(20 \%) \& 0 / 9(0 \%)$ respectively. Progressive disease was noted in $4 / 9(44 \%)$ of group 3 patients. There was striking differences between the groups with respect to clinical and pathological response.

Conclusion: In summary, CA 125 elimination half life measurement is a reproducible tool that can be used to assess chemotherapy sensitivity in patients with newly diagnosed advanced ovarian cancer following neoadjuvant chemotherapy. The CA 125 half life value is a helpful measurement that allows the clinicians to measure the degree of chemosensitivity prior to cytoreductive surgery.

\section{KEYWORDS : CA125, half life, advanced ovarian cancer}

\section{Background:}

Ovarian cancer is the third most common cancer in women and the second most common cause of cancer-related deaths from gynecologic malignancies worldwide (1). Incidences are higher in developed countries and among postmenopausal women (2). Symptoms for ovarian cancer are nonspecifific, causing to it being diagnosed when it has already developed into an advanced International Federation of Gynecology and Obstetrics (FIGO) stage and tumor cells have already disseminated into the peritoneal cavity and to other organs $(3)(4)$

Intraperitoneal spread of ovarian cancer is the most typical, earliest distribution pathway (5).Epithelial ovarian cancer (EOC) is the most lethal gynecologic malignancy with significant tumor recurrence and chemoresistance(6). Approximately $70-75 \%$ of patients are diagnosed at an advanced stage with widespread peritoneal disease(7).

At present, the gold standard for management is primary debulking surgery followed by platinum-based adjuvant chemotherapy. However, optimal debulking can be achieved in only $30-60 \%$ of stage III/IV ovarian cancers $(8)(9)(10)(11)$.

Neoadjuvant chemotherapy(NACT) followed by interval debulking surgery has been proposed as an alternative to conventional Primary Debulking surgery (PDS). These indications are for patients with a low probability of optimal cytoreduction or reversible contraindications

CA125 has been the most extensively studied and clinically utilized serum tumor marker. As a clinical tool, prognostic markers like CA125 may potentially help individualizing treatment within subgroups of patients. Serum levels of CA125 are used to monitor responses to chemotherapy, relapse, and disease progression in ovarian cancer patients .(12)

Levels of CA125 can be elevated in the serum even before gross clinical disease(13). The CA 125 elimination half life can be used as a measure of chemotherapy sensitivity in women with newly diagnosed advanced epithelial ovarian cancer who are being treated with neoadjuvant chemotherapy.

Identifying predictive markers of chemosensitivity at diagnosis or during the initial treatment phase may allow oncologists to tailor systemic and surgical treatments in the first line setting. Various groups have examined the significance of Ca125 in women with advanced high grade serous ovarian carcinoma being treated with primary cytoreductive surgery .(14)

CA125 expression is believed to correlate with tumor burden, therefore a decline in CA125 often indicates reduction in residual disease.

However, a significant proportion of patients cannot be optimally cytoreduced even after NACT-Interval Debulking Surgery(IDS) and this leads to the morbidity of surgery with no expected survival benefit (15)(16)(17). Although it is common practice to attempt Interval surgery only in patients responding to NACT, this approach causes several unnecessary laparotomies, if optimal cytoreduction cannot be achieved, and in other cases they are not applied also if the conditions are appropriate. Single variables have been combined into predictive cytoreduction models to improve accuracy in the settings of PDS (18) and recurrent disease (19)(20). Unfortunately, predictive models have not been developed for patients undergoing IDS.

Therefore, the aim of this study is to develop a predictive model of surgical outcome at IDS, to improve the selection of patients that can benefit of a maximal surgical effort.

\section{Methods:}

Medical records of women who were newly diagnosed with inoperable advanced ovarian cancer stages III and IV at our centre were selected. Only people with completely documented records in the years 2017 \& 2018 were selected. Clinical information on age, menopausal status, BMI, radiological PCI, stage, histology, chemotherapy drugs used, CA 125 levels before and after neoadjuvant chemotherapy were noted and information analysed.

Patients more than 70 years, incomplete data, receiving non standard chemotherapy were not included in the study.

Radiological assessment and CA 125 levels were repeated after 3 or 4 cycles of neoadjuvant chemotherapy (taxol plus carboplatin). Patietns with good radiological response and amenable to cytoreductive surgery were taken up for surgery. The findings at surgery and the pathological response to chemotherapy were noted.

At least two values of serum CA 125 were recorded before and after the completion of NACT. The time between two recordings(days) were 
noted. CA125 elimination half life was calculated using online web based calculators usin these two data. Technically the CA125 elimination half life is the time required for serum CA125 level to become half its original value under the influence of chemotherapy. The patients were divided into 3 sets based on CA 125 elimination half life $<10$ days, $10-20$ days and $>20$ days. The base line characters and outcomes of surgery and pathological responses were compared between these groups.

\section{RESULTS:}

A total of forty patients were analysed. The table shows the comparison between the three groups based on the CA 125 elimination half life. CA125 levels at beginning of treatment and at the end of 3 to 4 cycles of NACT were recorded and CA 125 half life calculated.

Optimal cytoredcution was possible in 19/21(90.4\%) patients in group $1,6 / 10(60 \%)$ in group $2 \& 2 / 9(22.2 \%)$ in group 3 . Clinical complete response was found in $12 / 21(57.1 \%), 2 / 10(20 \%) \& 0 / 9(0 \%)$ respectively. Progressive disease was noted in $4 / 9(44 \%)$ of group 3 patients.

Table 1: CA125 Elimination half life and patient parameters:

\begin{tabular}{|l|c|c|c|}
\hline Half life (days) & $\begin{array}{c}\text { Group 1 } \\
\text { T 1/2 } \\
<\mathbf{1 0} \text { days }\end{array}$ & $\begin{array}{c}\text { Group 2 } \\
\text { T 1/2 } \\
\mathbf{1 0 - 2 0} \text { days }\end{array}$ & $\begin{array}{c}\text { Group 3 } \\
\text { T 1/2 } \\
\mathbf{2 0} \text { days }\end{array}$ \\
\hline No. of Patients & 21 & 10 & 9 \\
\hline Age (years) & $62.5(54-69)$ & $63(56-66)$ & $61.5(53-66)$ \\
\hline $\begin{array}{l}\text { CA 125 (pre chemo) } \\
\text { range }\end{array}$ & $545-12453$ & $482-6033$ & $392-4554$ \\
\hline $\begin{array}{l}\text { CA 125 (post chemo) } \\
\text { range }\end{array}$ & $6-84 \mathrm{u} / \mathrm{ml}$ & $30-145 \mathrm{u} / \mathrm{ml}$ & $64-450 \mathrm{u} / \mathrm{ml}$ \\
\hline $\begin{array}{l}\text { Interval } \\
\text { cytoreductions } \\
\text { feasible after 3-4 } \\
\text { cycles }\end{array}$ & 19 & 6 & 2 \\
\hline $\begin{array}{l}\text { Interval } \\
\text { cytoreductions } \\
\text { feasible after 6 cycles }\end{array}$ & 2 & 4 & 3 \\
\hline $\begin{array}{l}\text { Clinical complete } \\
\text { response }\end{array}$ & 12 & 2 & 0 \\
\hline $\begin{array}{l}\text { Pathological } \\
\text { complete response }\end{array}$ & 9 & 1 & 0 \\
\hline $\begin{array}{l}\text { Inoperable/ } \\
\text { progressive disease }\end{array}$ & 0 & 0 & 4 \\
\hline
\end{tabular}

\section{DISCUSSION:}

Gynecologic oncologists often rely on surrogate indicators including tumor markers and imaging assessment. These assessment tools have inherent limitations and lack precision and accuracy.

Diagnostic laparoscopy provides a more accurate measure of disease volume and disease distribution. Patients with favorable scores on laparoscopic assessment, which are predictive of tumor resectability, undergo cytoreductive surgery. Those with unfavorable scores are not taken for attempted cytoreduction thus avoiding futile laparotomy.

Nonetheless, diagnostic laparoscopy has not been widely adopted. Some of its limitations include the increased cost associated with the procedure, the added surgical resource, possible complications associated with the general anesthetic, and the delay to definitive treatment. Therefore, non-resource intensive, accurate markers of surgical resectability are critically needed in advanced ovarian cancer.

In patients with substantial platinum sensitivity, platinum-based therapy may have a larger impact on survival than the degree of surgical resection at cytoreductive surgery.

This finding suggests that tumors that are less sensitive to chemotherapy appear more reliant on the degree of surgical resection where complete resection harbors significant survival advantage. This knowledge might be of great importance to the gynecologic oncology surgeons as the tumor marker half life value may aid in pre-operative and intra-operative decision-making.

A shorter elimination half life indicates faster tumor elimination rate and hence higher chemotherapy sensitivity. Chemosensitivity is an important predictor of survival in ovarian malignancies. To date, a commonly used indicator of platinum sensitivity is the platinum free interval which measure the time lapse between the last platinum treatment and the date of recurrence. This measure is helpful in selecting second line therapies in recurrent ovarian carcinoma. It is however a retrospective measure and therefore isn't applicable in the first line setting.

Our study has established striking differences in the radiological, clinical and pathological response to NACT based on the CA125 half life. The study has its own limitations. Being retrospective in nature and the small sample size may limit statistical significance.

\section{CONCLUSION:}

In patients with long CA 125 elimination half life, who are reliant on surgical completeness, prolonged surgery, mutlivisceral resection and increased surgical morbidity might be acceptable in favor of improved survival.

However, the role of aggressive surgery and the added benefit harbored by complete cytoreduction in women with favorable score deserves further studying.

In summary, Ca 125 elimination half life measurement is a reproducible tool that can be used to assess chemotherapy sensitivity in patients with newly diagnosed advanced ovarian cancer following neoadjuvant chemotherapy. The Ca 125 half life value is a helpful measurement that allows the clinicians to measure the degree of chemosensitivity prior to cytoreductive surgery.

This can aid in surgical decision making regarding the role and extent of interval cytoreduction as well as alternate systemic therapies. This knowledge may allow for individualized treatment plans for women with advanced epithelial ovarian cancer based on their CA 125 scores.

\section{REFERENCES:}

1. Jemal A, Bray F, Center MM, Ferlay J, Ward E, Forman D. Global cancer statistics. CA Cancer J Clin. 2011;61(2):69-90. - Google Search [Internet]. [cited 2020 Jul 27]. Available from:

2. Holschneider $\mathrm{CH}$, Berek JS. Ovarian cancer: Epidemiology, biology, and prognostic factors. Vol. 19, Seminars in Surgical Oncology. 2000.p. 3-10.

3. Heintz AP, Odicino F, Maisonneuve P, et al. Carcinoma of the ovary. FIGO 26th Annual Report on the Results of Treatment in Gynecological Cancer. Int J Gynaecol Obstet. 2006;95(Suppl 1):S161-92.

4. Engel J, Eckel R, Schubert-Fritschle G, Kerr J, Kuhn W, Diebold J, et al. Moderate progress for ovarian cancer in the last 20 years: Prolongation of survival, but no improvement in the cure rate. Eur J Cancer. 2002 Dec;38(18):2435-45.

5. Meyers MA. Distribution of intra abdominal malignant seeding: dependency on dynamics of flow of ascitic fluid. AMERJROENTGENOL [Internet]. 1973 Sep [cited 2020 Jul 27];119(1):198-206. Available from: http:// www. ajronline. org/doi/ 10.2214/ ajr.119.1.198

6. Lowe KA, Chia VM, Taylor A, O'Malley C, Kelsh M, Mohamed M, et al. An international assessment of ovarian cancer incidence and mortality. Gynecol Oncol. $2013 \mathrm{Jul} ; 130(1): 107-14$.

7. Mercieca-Bebber R, Friedlander M, Kok PS, Calvert M, Kyte D, Stockler M, et al. The patient-reported outcome content of international ovarian cancer randomised controlled trial protocols. Qual Life Res. 2016;25(10):2457-65. -

8. Griffiths CT. Surgical resection of tumor bulk in the primary treatment of ovarian carcinoma. Natl Cancer Inst Monogr. 1975;42:101-4. - Google Search [Internet]. [cited 2020 Jul 27].

9. Chang S-J, Bristow RE, Chi DS, Cliby WA. Role of aggressive surgical cytoreduction in advanced ovarian cancer. J Gynecol Oncol [Internet]. 2015 Oct 1 [cited 2020 Jul 27];26(4):336. Available from: https:// ejgo. org/ DOIx. php?id=10.3802/ jgo.2015.26.4.336

10. Dauplat J, Le Bouedec G, Pomel C, Scherer C. Cytoreductive surgery for advanced stages of ovarian cancer. Semin Surg Oncol. 2000;19(1):42-8. Gao et al. Journal of Ovarian Research (2019) 12:85 Page 7 of 88. Lee YJ, Chung YS, Lee JY, Nam EJ, Kim $\mathrm{SW}$, Kim S, et al. Impact of increased utilization of neoadjuvant chemotherapy on survival in patients with -

11. Tseng JH, Cowan RA, Zhou Q, Iasonos A, Byrne M, Polcino T, et al. Continuous improvement in primary Debulking surgery for advanced ovarian cancer: do increased complete gross resection rates independently lead to increased progression-free and complete gross resection rates independently lead to increased progression-free and
overall survival? Gynecol Oncol. 2018;151(1):24-31.

12. O'Brien TJ, Beard JB, Underwood LJ, Dennis RA, Santin AD, York L: The CA 125 gene: an extracellular superstructure domi nated by repeat sequences. Tumour Biol 2001, 22:348-366.

13. Burger RA, Darcy KM, DiSaia PJ, Monk BJ, Grosen EA, Gatanaga T, Granger GA, Wang J, Tian C, Hanjani P, Cohn DE: Association between serum levels of soluble tumor necrosis factor receptors/CA 125 and disease progression in patients with epithelial ovarian malignancy: a gynecologic oncology group study. Cancer 2004, 101:106-115. -

14. May T, Stewart JM, Bernardini MQ, Ferguson SE, Laframboise S, Jiang H, et al. The prognostic value of perioperative, pre-systemic therapy CA125 levels in patients with prognostic value of perioperative, pre-systemic therapy CA125 levels in patients with
high-grade serous ovarian cancer. Int J Gynecol Obstet. $2018 \mathrm{Feb} 1 ; 140(2): 247-52$.

15. Tangjitgamol S, Manusirivithaya S, Laopaiboon M, Lumbiganon P, Bryant A. Interval debulking surgery for advanced epithelial ovarian cancer. Cochrane Database Syst Rev. 2016; no. 1, p. CD006014, Valadares CV, Baiocchi G, Mantoan H, Saito A, Sanches S, et al. Neoadjuvant chemotherapy followed by interval Debulking surgery and the risk of platinum resistance in epithelial ovarian Cancer. Ann Surg Oncol. 2015;22(Suppl 3):S971-8. -

16. Pepin K, Bregar A, Davis M, Melamed A, Hinchcliff E, Gockley A, et al. Intensive care admissions among ovarian cancer patients treated with primary debulking surgery and neoadjuvant chemotherapy-interval debulking surgery. Gynecol Oncol. 2017 Dec 1;147(3):612-6.

17. Aletti GD, Dowdy SC, Podratz KC, Cliby WA. Relationship among surgical complexity, 
short-term morbidity, and overall survival in primary surgery for advanced ovarian cancer. Am J Obstet Gynecol [Internet]. 2007 [cited 2020 Jul 27];197(6):676.e1-676.e7. Available from: https://pubmed.ncbi.nlm.nih.gov/18060979/

18. Rutten MJ, Van De Vrie R, Bruining A, Spijkerboer AM, Mol BW, Kenter GG, et al. Predicting surgical outcome in patients with international federation of gynecology and obstetrics stage III or IV ovarian cancer using computed tomography: A systematic review of prediction model [Internet]. Vol 25, International Journal of Gynecological Cancer. Lippincott Williams and Wilkins; 2015 [cited 2020 Jul 27]. p. 407-15. Available Cancer. Lippincott Williams and Wilkins; 2015 [cited
from: https://pubmed.ncbi.nlm.nih.gov/25695545/

19. Harter P, Sehouli J, Reuss A, Hasenburg A, Scambia G, Cibula D, et al. Prospective validation study of a predictive score for operability of recurrent ovarian cancer: The multicenter intergroup study DESKTOP II. A project of the AGO kommission OVAR, AGO study group, NOGGO, AGO-Austria, and MITO. Int J Gynecol Cancer [Internet]. 2011 [cited $2020 \mathrm{Jul}$ 27];21(2):289-95. Available from: https:// pubmed. ncbi. nlm. nih.gov/21270612

20. Van de Laar R, Zusterzeel PLM, Van Gorp T, Buist MR, Van Driel WJ, Gaarenstroom $\mathrm{KN}$, et al. Cytoreductive surgery followed by chemotherapy versus chemotherapy alone for recurrent platinum-sensitive epithelial ovarian cancer (SOCceR trial): A multicenter randomised controlled study. BMC Cancer [Internet]. 2014 Jan 14 [cited 2020 Jul randomised controlled study. BMC Cancer [Internet]. 2014 Jan 14 [cited $2020 \mathrm{Jul}$
27];14(1):22. Available from: http:// bmccancer. biomedcentral. com/ articles/ 27];14(1):22. Available
$10.1186 / 1471-2407-14-22$ 